\title{
TCOM \\ COVID-19 and science communication: a JCOM special issue. Part 2
}

\section{Luisa Massarani, Padraig Murphy and Rod Lamberts}

\begin{abstract}
As COVID-19 continues its devastating pathway across the world, in this second part of the JCOM special issue on communicating COVID-19 and coronavirus we present further research papers and practice insights from across the world that look at specific national challenges, the issue of "fake news" and the possibilities of satire and humour in communicating the seriousness of the deadly disease.
\end{abstract}

Keywords

DOI
Science and media; COVID-19; Coronavirus

https://doi.org/10.22323/2.19070501

Submitted: 30th October 2020

Accepted: 1st November 2020

Published: 14th December 2020

This second edition of the special issue of JCOM on COVID-19 and science communication presents a further nine research articles and two practice insights continuing our investigation into the challenges of communicating COVID-19. In Part 1 of this issue on COVID-19 and science communication, we reported how a simple word search on 17 August 2020 for 'COVID-19' on the Scopus database of scientific papers retrieved 18,799 articles. As we write this on $28^{\text {th }}$ October, the same search on Scopus retrieves 33,750 research articles. On September $10^{\text {th }}$, the date of publication of Part 1, we reported that 28 million people were affected worldwide with more than 910,000 deaths according to Worldometer. ${ }^{1}$ Today, there are over 44 million cases and over 1.1 million deaths. While Asia suffered a "second wave" during the summer months, Europe is now in the middle of a new surge while the Americas are still in the first, South America in particular enduring a continuous wave. While Australia, New Zealand and the surrounding regions appear to have halted a second wave, Africa waits in anticipation for the next onslaught. COVID-19 continues its devastation and with restricted movements and partial and full lockdowns enforced locally and reduced only to be re-instated again, the societal and political impact of these yo-yo effects still dominate news media and policy across the world.

As with Part 1, there is a truly global reach across our selected research papers exploring the localised impact of the crisis, such as Surjit Singh and Gauhar Raza's

\footnotetext{
${ }^{1}$ Worldometer https: / / www.worldometers.info/coronavirus / (accessed 28 October 2020).
} 
survey of the Indian public on their perceptions, hopes and rejection of conspiracies and Fredj Zamit and colleagues's study of fact-checking in Tunisia. Reymund Flores and Xavier Venn Asuncion found increasing trust among Philippine publics in communicating risk across social media. By contrast, the rapid spread of the so-called "infodemic" about hydroxychloroquine and chloroquine in Brazil was analysed by Ana Carolina Monari and colleagues looking at the challenge of fact-checking President Bolsanaro's Facebook "lives" addresses, while Thales Brandi Ramos and co-authors examined these COVID-19 treatments on YouTube. Luisa Massarani and co-authors analysed accuracy and reliability on social media and news media in Brazil.

Humour, satire and COVID-19's embeddedness in popular culture allow close examination of how health science communication might work differently than it has before the pandemic. Marina Joubert and Herman Wasserman look at how newspaper cartoonists portray the coronavirus in South Africa while comic-based risk communication of COVID-19 pandemic is also the subject of the paper from Yasumasa Igarashi and colleagues. Rick Pulos applies Rhetorical Arena Theory to identify crisis memes that use humour, while a prescient "space plague" game developed and reported by Lindsay Keith and Wyn Griffiths was took on a different pathway as reality exceeded the imagination. Finally, the COVID-19 crisis affords Michelle Riedlinger and co-authors the opportunity to reflect on science-society relationships across 11 countries and cultures since the pandemic began.

Once again, we would like to thank most enthusiastically the more than 200 researchers and practitioners around the world who helped us to review the articles. A special thank you also to Cristiana Prever and the editorial team for all the support in developing this two-part special issue.

\section{Authors}

Luisa Massarani is a Brazilian science communicator who carries out both practical and research activities in the field. She is the coordinator of the National Brazilian Institute of Public Communication of Science and Technology, the master in Science Communication at House of Oswaldo Cruz/Fiocruz (Brazil) and for Latin American SciDev.Net. She is recipient of the Mercosur Award for Science and Technology (2014), the Brazilian Award for Science Communication (2016) and the Literature Jabuti Award (2017). E-mail: luisa.massarani6@gmail.com.

Padraig Murphy is Assistant Professor in Communication at Dublin City University and Chair of the MSc in Science and Health Communication programme. His teaching and research interests include science communication, science and technology studies and public engagement with science and technology. He is author of Biotechnology, Education and Life Politics: Debating Genetic Futures from School to Society (Routledge, 2014) and co-author of Little Country, Big Talk: Science Communication in Ireland (2017). E-mail: padraig.murphy@dcu.ie.

Rod Lamberts is Deputy Director of the Australian National Centre for the Public Awareness of Science (CPAS) at the Australian National University and a former National President of the Australian Science Communicators. He has more than two decades' experience as a science communication practitioner and researcher and designed and delivered some of the first university science communication 
courses in the world. Rod has provided science communication advice to a wide variety of private and public science-related agencies in Australia and overseas, and is a regular public commentator on science and, science communication in the Australian media. His professional and research interests include: science communication and public intellectualism/activism; science and ethics; perceptions of expertise in science; risk perception and communication; and science and public policy. He is also the co-host of the galactically renowned science-ish podcast 'The Wholesome Show'. E-mail: rod.lamberts@anu.edu.au.

How to cite

Massarani, L., Murphy, P. and Lamberts, R. (2020). 'COVID-19 and science communication: a JCOM special issue. Part 2'. JCOM 19 (07), E. https://doi.org/10.22323/2.19070501. 